\title{
The Effect of Iron Deficiency Anemia on Glycated Hemoglobin (HbA1c) in Non Diabetic Adults
}

\author{
Singh P, Singhal S, Virmani S.K. \\ Post Graduate Department Of Medicine,Subharti Medical College,Meerut
}

\begin{abstract}
Background: Iron deficiency anemia is the most common form of anemia in India. Hemoglobin Alc (HbAlc) is used in diabetic patients as an index of glycemic control reflecting glucose levels of the previous 3 months. Like blood sugar levels, HbAlc levels are also affected by the presence of variant hemoglobins, hemolytic anemias, nutritional anemias, uremia, pregnancy, and acute blood loss. Previous studies suggest that iron deficiency anemia (IDA) affects the levels of HbAlc. We conducted study to analyze the effect of iron deficiency anemia on glycated hemoglobin $(H b A l c)$ in non diabetic Indians.

Methods: 30 randomly selected non-diabetic patients with confirmed iron deficiency anemia will be compared with 30 randomly selected cases without diabetes and without Iron deficiency anemia healthy adults.
\end{abstract}

\section{Introduction}

Hemoglobin A1c (HbAlc) is a glycated hemoglobin that can be used as an indicator of a patient's glycemic status over the previous 3 months. Glycated hemoglobins, including HbA1c and other hemoglobins, constitute the $\mathrm{HbA} 1$ fraction of adult hemoglobin (HbA) [1]. According to the American Diabetes Association (ADA) guidelines, the value of HbA1c should be kept below $6.5 \%$ in all the diabetics. The values which are greater than $6.5 \%$ indicate an increased chance of progression to the diabetic complications, especially the microvascular ones[2]. HbA1c levels are not affected by blood glucose levels alone. They are also altered in hemolytic anemias, hemoglobinopathies, acute and chronic blood loss , pregnancy, and uremia , Vitamin B12, folate, and iron deficiency anemias have also been shown to affect HbAlc levels[3]. The two known factors which can modulate the glycation of proteins are the prevailing concentration of glucose and the half life of the protein[4]. But evidences in the literature have documented increased glycated protein levels in some nondiabetic pathological states, like iron deficiency anemia. Some authors have also found that on supplementation with iron therapy, there was a significant decrease in the levels of glycated haemoglobin[5]. Evidence has accumulated, which supports the hypothesis that the glycation reaction, apart from the traditional chronic hyperglycaemia ,can be modulated by the iron status of the patient. If the degree of glycation of other proteins in anemic patients was similar to that of the glycated haemoglobin, it would have important clinical implications.

Some studies show that HbA1c levels are increased in iron deficiency anemia and attempted to explain on the basis of both modifications to the structure of haemoglobin and level of HbA1c in old and new red blood cells[6]. Some Study showed that HbA1c levels were higher in patients of iron deficiency anemia and decreased significantly upon treatment with iron[7]. With this background, the objective of the present study was to study the effect of iron deficiency anemia on glycated hemoglobin (HbA1c) in non diabetic Indian subjects. If so, the iron deficiency had to be corrected before any diagnostic or therapeutic decision was made based on the HbA1c level.

\section{Aims and Objectives}

1.) To study the effect of iron deficiency anemia on glycated hemoglobin (HbAlc) in non diabetic Indian subjects.

2) A Comparision Study of Normal Healthy Adults without Iron Deficiency anemia.

\section{Methods}

30 randomly selected non-diabetic patients with confirmed iron deficiency anemia will be compared with 30 randomly selected cases without diabetes and without Iron deficiency anemia healthy adults who attended the Medicine department at Subharti Hospital were included in the study, on the basis of strict inclusion and exclusion criterias as mentioned below.

All the participants were also informed about the study procedure and the information required from them for the study. A voluntary informed written consent was taken from the participant those who consented were included in the study. 


\section{Inclusion Criteria}

1) Anemia with haemoglobin $<13.5 \mathrm{~g} / \mathrm{dl}$ in males and $<12.0 \mathrm{~g} / \mathrm{dl}$ in females and ferritin less than $10 \mathrm{~g} / \mathrm{dl}$.

2) Age $\geq 18$ years

3) Both sexes included

\section{Exclusion Criteria}

1) Pregnancy

2) Haemolytic anemia

3) Diabetics or Impaired glucose tolerance or fasting blood sugar $>100 \mathrm{mg} / \mathrm{dl}$.

4) Haemoglobinopathies

5) End stage kidney disease.

6) End stage liver disease.

7) Confirmed case of malignancies

A detailed history like age, gender and clinical symptoms and examination was taken and physical examination was performed of the patients. The information regarding laboratory parameters like Hemoglobin, $\mathrm{MCV}, \mathrm{MCH}, \mathrm{MCHC}$, TLC, Iron profile(serum iron,Total Iron Binding Capacity and serum ferritin), fasting blood sugar level, Random blood sugar level, HbA1c, liver and renal function tests were also noted.

\section{Statistical analysis:}

The frequency distribution and graph were prepared for the variables. The $\mathrm{P}$ value and chi square test were used wherever appropriate to analyze the data and were calculated to find correlation between two variables. Mantel Hanzel Odds Ratio (OR) and corresponding 95\% Confidence Interval (CI) were calculated for dichotomous variables. A $\mathrm{p}<0.05$ was considered statistically significant.

\section{Results}

The present study was conducted among 30 cases having Iron deficiency anemia and 30 apparently healthy controls without iron deficiency anemia. All cases and controls are non diabetic.

\section{1: Comparison of Age in Case (IDA)s and Control (Healthy)}

In case group highest cases were in 18-30 years of age while in control group highest cases were in 3140 years age group. Application of statistical test indicate that the difference of age between case and control group was statistically non significant $(\mathrm{p}>0.05)$

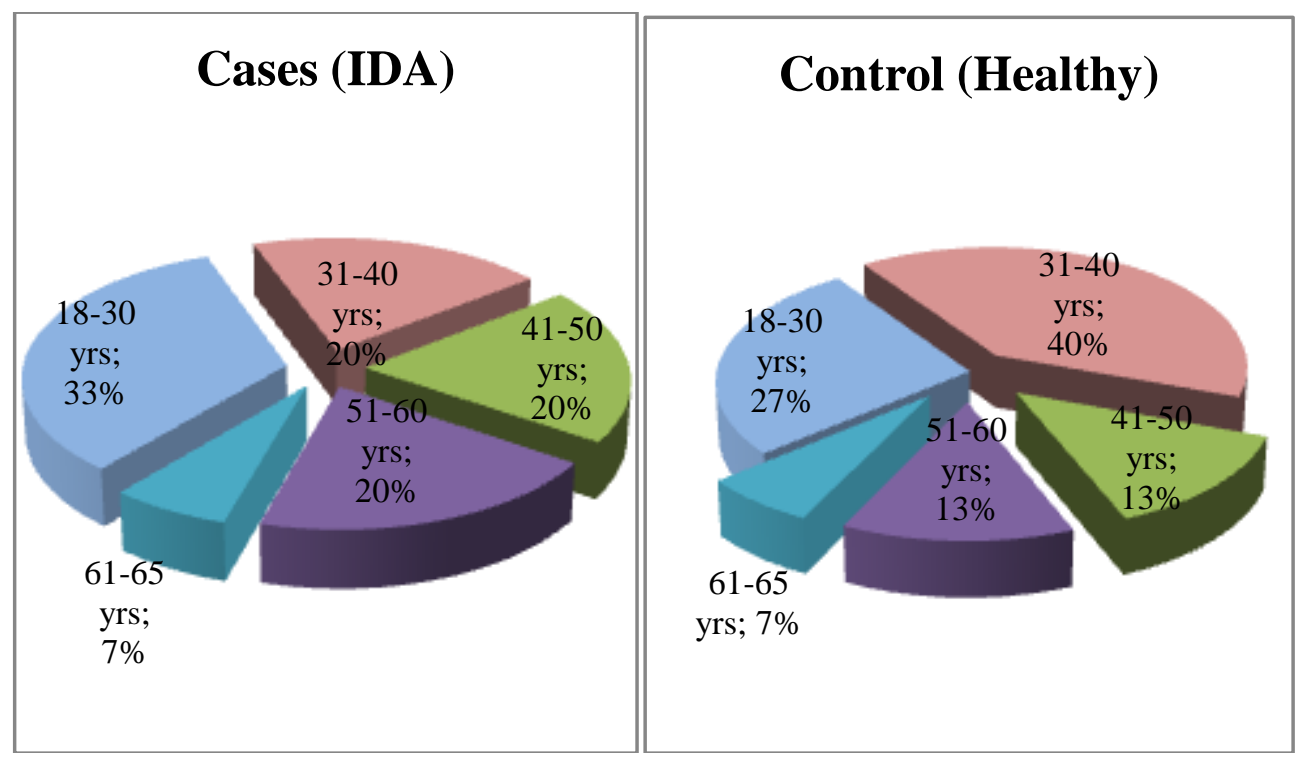

Figure 1: Comparison of mean age in Case (IDA)s and Control (Healthy)

In case group highest cases were in 18-30 years of age while in control group highest cases were in 31-40 years age group. 


\section{2: Sex wise distribution of Cases (IDA) and Control (Healthy)}

In the case group male were $33.33 \%$ while in control group male were $50 \%$. However, the difference was non significant as the $\mathrm{p}$ value was $>0.05$.

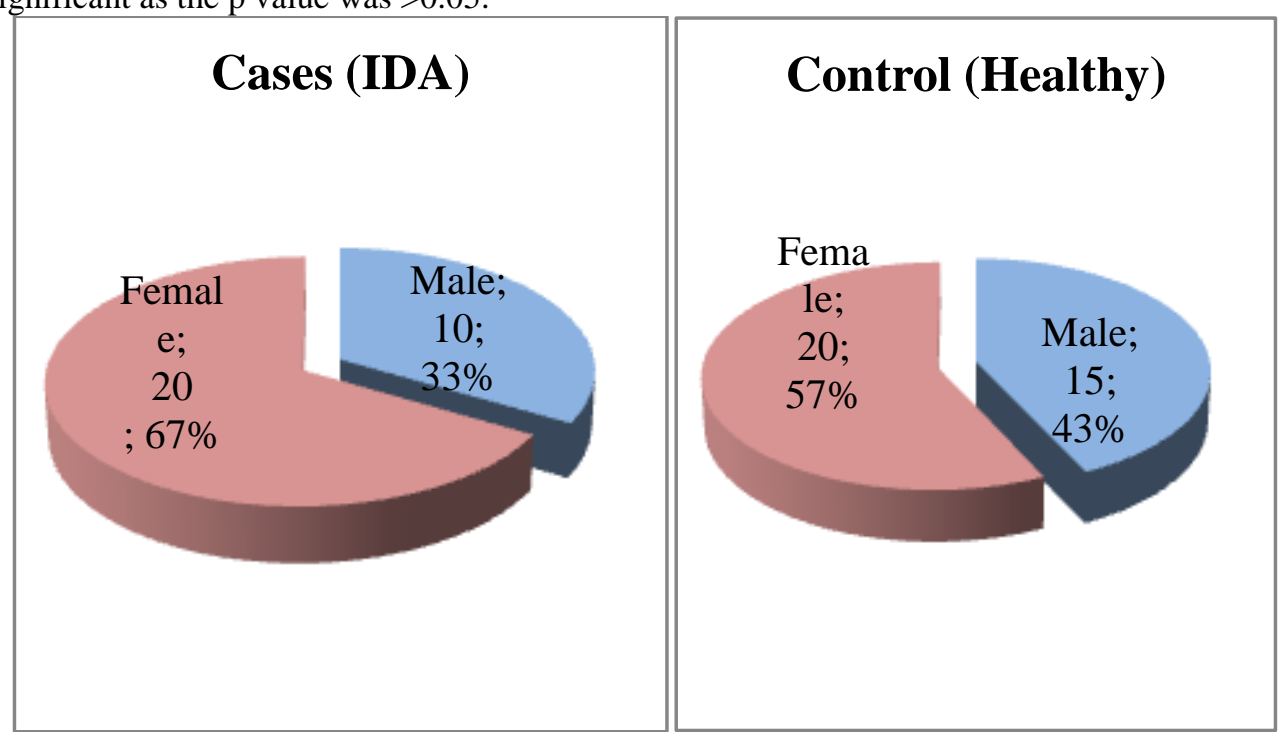

Fig 2: Sex wise distribution of Cases (IDA) and Control (Healthy)

\section{3: Comparison of mean $\mathrm{Hb}$ in gm\% in Case (IDA)s and Control (Healthy)}

\begin{tabular}{|l|l|l|l|}
\hline Variable & Case (IDA) & Control (Healthy) & Total \\
\hline $\mathrm{n}$ & 30 & 30 & 60 \\
\hline $\begin{array}{l}\text { Hb in gm\% } \\
(\text { Mean } \pm \text { SD) }\end{array}$ & $6.07 \pm 1.89$ & $13.43 \pm 0.85$ & $9.75 \pm 3.98$ \\
\hline P value* & $<0.001$ & \\
\hline
\end{tabular}

*Calculated by using ' $\mathrm{t}$ ' test. $\mathrm{P}$ value $<0.01$ significant

Above table shows mean $\mathrm{Hb}$ in gm $\%$ and standard deviation of $\mathrm{Hb}$ in gm $\%$ among Cases (IDA group) and Control (Healthy group). The mean $\mathrm{Hb}$ in gm $\%$ of cases was $6.07 \mathrm{mg} \%$ while it was $13.43 \mathrm{gm} \%$ in healthy control.

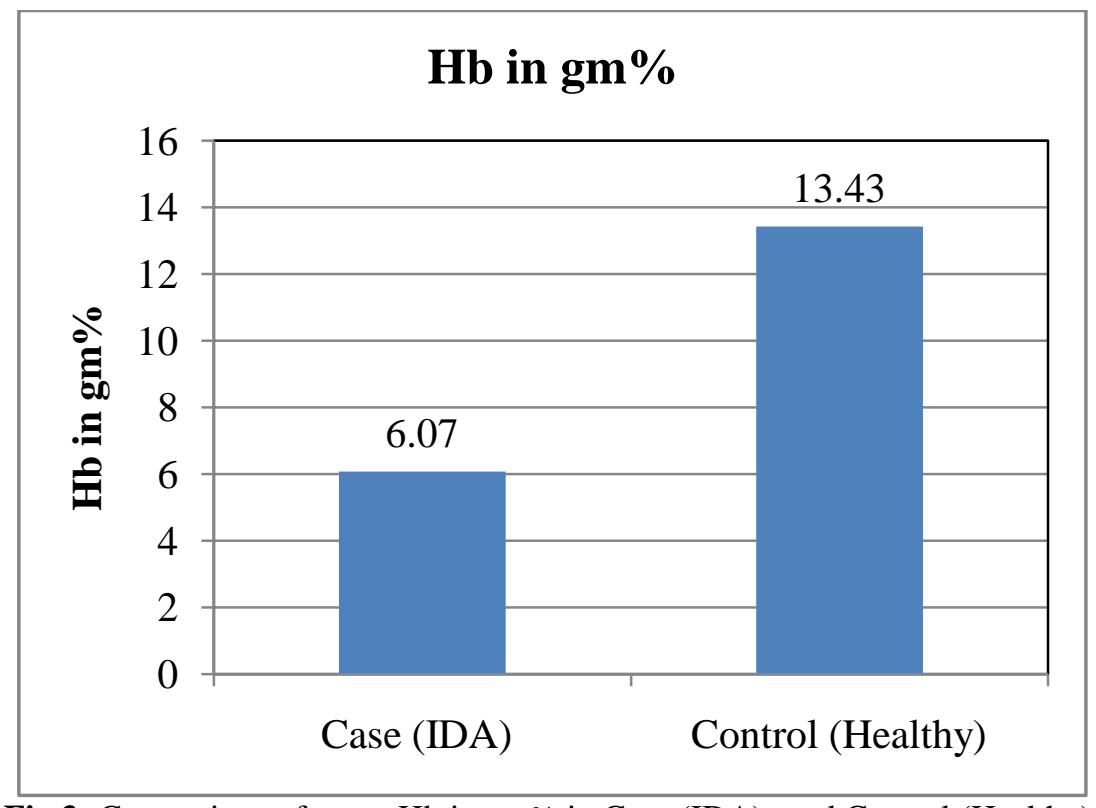

Fig 3: Comparison of mean $\mathrm{Hb}$ in gm\% in Case (IDA)s and Control (Healthy). 


\section{4: Comparison of Serum Ferritin in Case (IDA)s and Control (Healthy)}

\begin{tabular}{|l|l|l|l|}
\hline Variable & Case (IDA) & Control (Healthy) & Total \\
\hline $\mathrm{n}$ & 30 & 30 & 60 \\
\hline $\begin{array}{l}\text { S. Ferritin (ng/mL) } \\
\text { Mean } \pm \text { SD) }\end{array}$ & $8.74 \pm 1.79$ & $90.24 \pm 13.49$ & $49.49 \pm 42.19$ \\
\hline P value* & $<0.001$ & \\
\hline
\end{tabular}

*Calculated by using ' $\mathrm{t}$ ' test. $\mathrm{P}$ value $<0.01$ significant

Above table shows mean S. ferritin and standard deviation of S. ferritin among Cases (IDA group) and Control (Healthy group). The mean S. ferritin of cases was $8.74 \mathrm{ng} / \mathrm{ml}$ while it was $90.24 \mathrm{ng} / \mathrm{ml}$ in healthy control. Application of statistical test shows that the difference of S. ferritin between case and control group was statistically significant $(\mathrm{p}<0.05)$ indicating significantly lower $\mathrm{S}$. ferritin level in case group compare to control group.

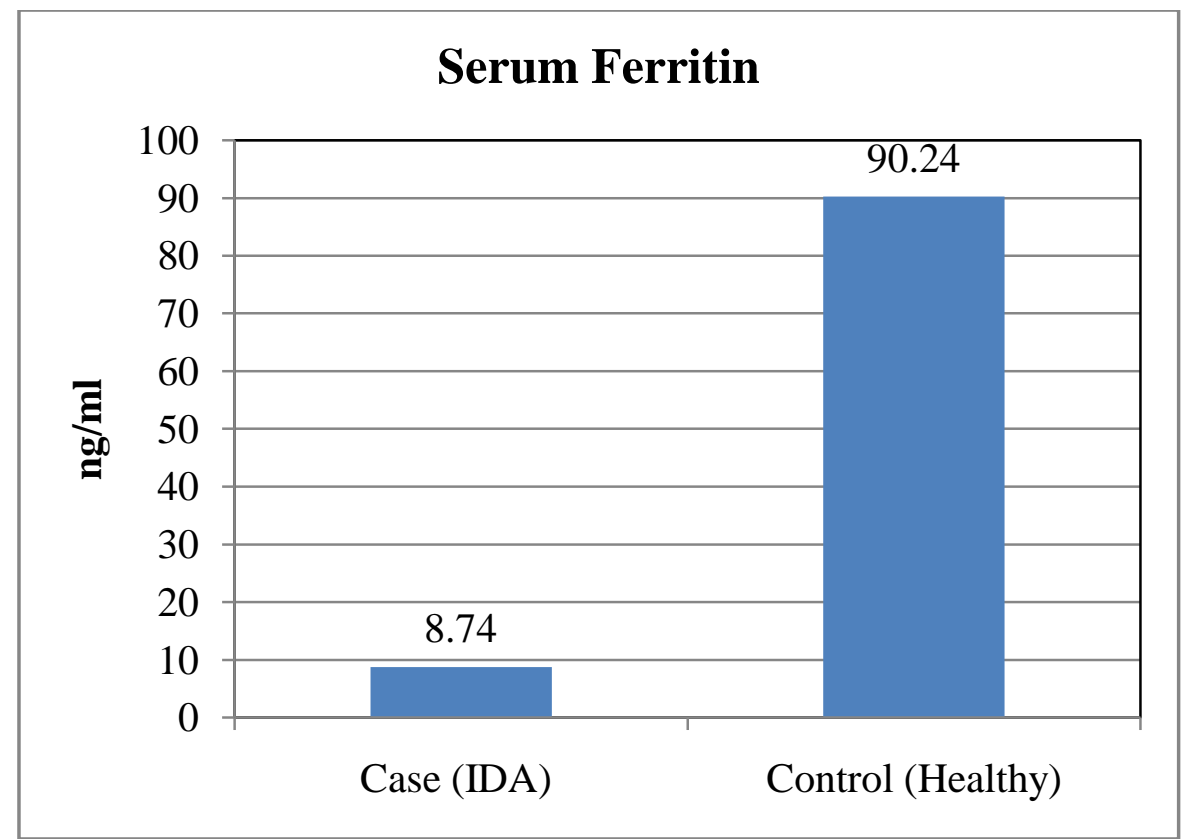

Figure 4: Comparison of Serum Ferritin in Case (IDA)s and Control (Healthy)

\section{5: Comparison of mean HbAc in Case (IDA)s and Control (Healthy)}

\begin{tabular}{|l|l|l|l|}
\hline Variable & Case (IDA) & $\begin{array}{l}\text { Control } \\
\text { (Healthy) }\end{array}$ & Total \\
\hline $\mathrm{n}$ & 30 & 30 & 60 \\
\hline $\begin{array}{l}\text { HbA1C } \\
\text { Mean } \pm \text { SD) }\end{array}$ & $5.87 \pm 0.12$ & $5.03 \pm 0.18$ & $5.45 \pm 0.45$ \\
\hline P value* & $<0.001$ & \\
\hline
\end{tabular}

*Calculated by using ' $\mathrm{t}$ ' test. $\mathrm{P}$ value $<0.01$ significant

Above table shows mean HbA1c and standard deviation of HbA1c among Cases (IDA group) and Control (Healthy group). The mean HbA1c of cases was $5.87 \%$ while it was $5.03 \%$ in healthy control. Application of statistical test shows that the difference of HbA1c between case and control group was statistically significant $(\mathrm{p}<0.01)$ indicating statistically higher HbA1c in cases group. 


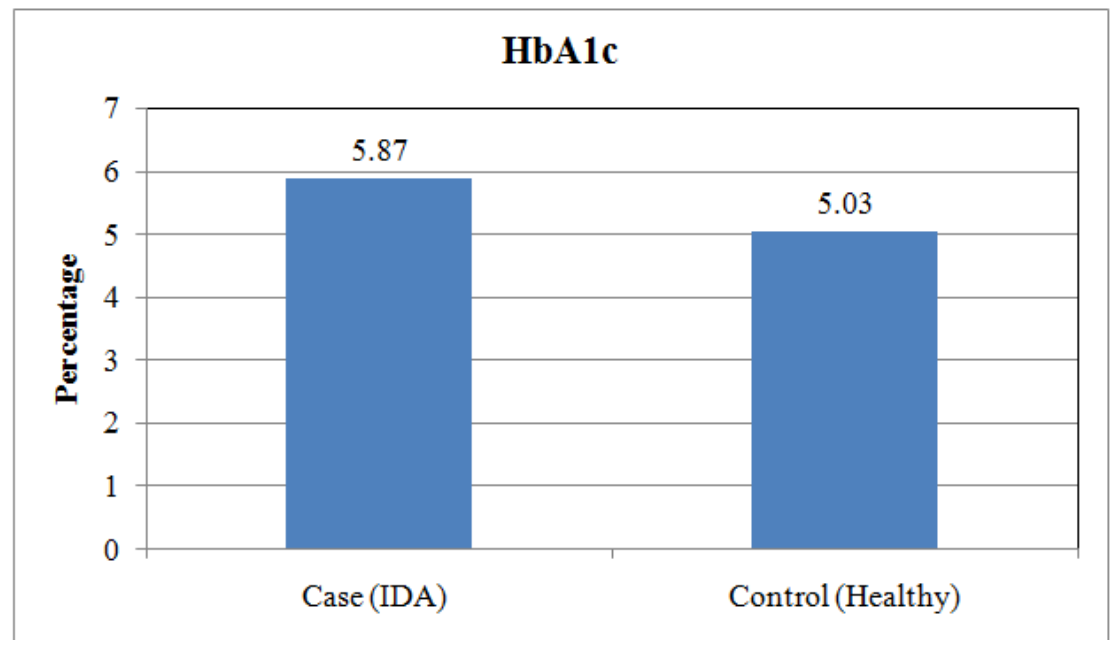

Figure 5: Comparison of mean HbA1c in Case (IDA)s and Control (Healthy).

Below graph shows correlation of HbA1c with hemoglobin level in iron deficiency cases. A scattered dot plot diagram was prepared with having HbA1c in $\mathrm{x}$ axis and hemoglobin in $\mathrm{y}$ axis. The graph also shows best-fit linear regression line

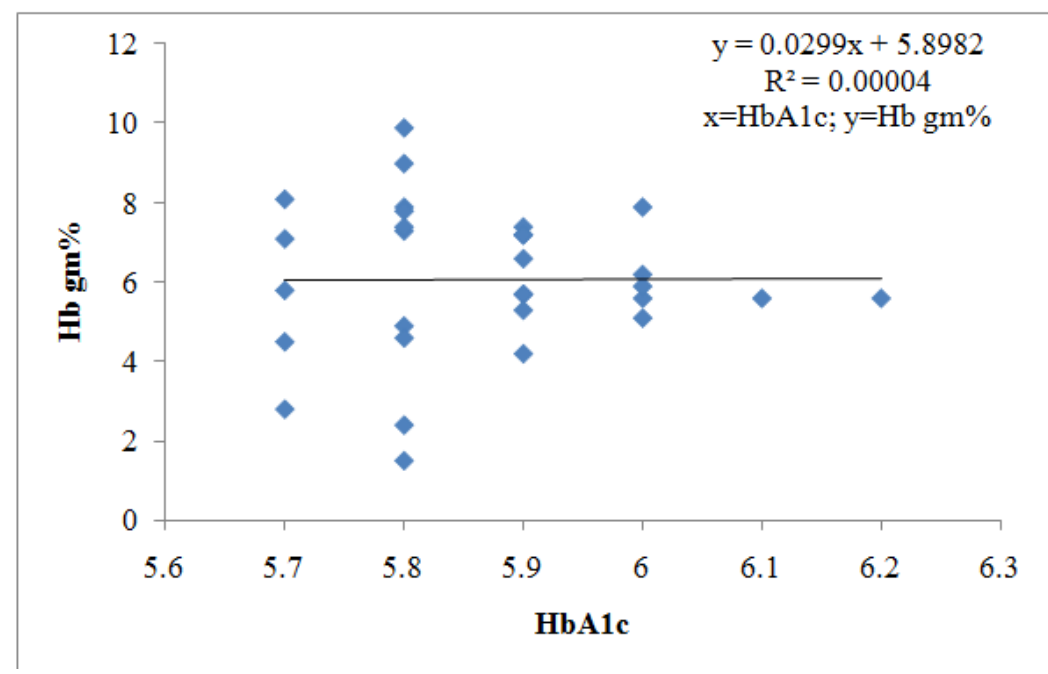

Fig 6: Correlation of Hemoglobin and HbA1c

\section{Discussion}

Our results suggested that IDA was associated with higher concentrations of HbA1c. The mean HbA1c of cases was $5.87 \%$ while it was $5.03 \%$ in healthy control. Application of statistical test shows that the difference of $\mathrm{HbA} 1 \mathrm{c}$ between case and control group was statistically significant $(\mathrm{p}<0.01)$ indicating statistically higher HbA1c in cases group.

In the study conducted by Vishal Kalasker et al ,[8] the mean HbA1c of cases was $5.91 \pm 0.47 \%$ while it was $6.54 \pm 0.39 \%$ in healthy control. Application of statistical test shows that the difference of HbA1c between case and control group was statistically significant $(\mathrm{p}<0.01)$ indicating statistically higher HbA1c in control group.

In the study conducted by Balasubramanian Shanthi et al ,[9]the mean HbA1c of cases was $7.6 \pm 0.5$ $\%$ while it was $5.5 \pm 0.8 \%$ in healthy control. Application of statistical test shows that the difference of HbA1c between case and control group was statistically significant $(\mathrm{p}<0.01)$ indicating statistically higher HbA1c in cases group.

In the study conducted by Alap L. Christy et al , [10]the mean HbA1c of cases was $6.87 \pm 1.4 \%$ while it was $5.65 \pm 0.69 \%$ in healthy control. Application of statistical test shows that the difference of HbA1c between case and control group was statistically significant $(\mathrm{p}<0.01)$ indicating statistically higher HbA1c in cases group. 
Hansen et al.,[11]showed normal HbA1c concentrations in iron deficiency, which dropped to subnormal levels after iron supplementation. Rai et al.,[12] investigated the different methods and no difference was detected among the colorimetric methods, ion-exchange chromatography and affinity chromatography.

Our results suggested that IDA was associated with higher concentrations of HbA1c. Similarly, Brooks et al.,[13] showed higher HbA1c concentrations in iron-deficient nondiabetic adults, which decreased to normal. In anaemic patients, the concentration of glycated haemoglobin has been reported to be increased despite the shortened life span of the erythrocytes. Several mechanisms have been advocated for this increase in the levels of glycated haemoglobin in anaemic patients. It has been proposed that in iron deficiency, the quaternary structure of the haemoglobin molecule may be altered, and that the glycation of the $\beta$-globin chains occurs more readily.

This study has got a significant relevance because iron deficiency anemia is very highly prevalent in a tropical country like India.. HbA1c is commonly used to assess the long-term blood glucose control in the patients with diabetes mellitus[14].

\section{Conclusion}

Our results showed that iron deficiency was associated with higher proportions of HbA1c, which could cause problems in the diagnosis of uncontrolled diabetes mellitus in iron-deficient patients. The iron status must be considered during the interpretation of the HbA1c concentrations in Diabetes mellitus. The iron replacement therapy is thus especially important in diabetic patients with iron deficiency, as it would also increase the reliability of the HbA1c determinations.

\section{References}

[1]. Telen MJ, Kaufman RE. The mature erythrocyte. In: Greer JP, Forester J, et al., editors. Wintrobe's clinical hematology. 11th ed. Lippincot: Williams and Wilkins; 2004. p. 230

[2]. American Diabetes Association. Standards of medical care in diabetes-2016. Diabetes Care. 2016;39(suppl 1):S1- S106.

[3]. Starkman HS, wacks M, Soeldner JS, Kim A. Effect of acute blood loss on glycosylated hemoglobin determination in normal subjects. Diabetes care 1983;6:291-4

[4]. Mayer TK, Freedman ZR. Protein glycosylation in diabetes mellitus: a review of the laboratory measurements and their clinical utilities. Clin Chim Acta. 1983;127:147e84

[5]. Chowdhury TA, Lasker SS. The elevated glycated haemoglobin in nondiabetic patients is associated with an increased mortality in myocardial infarction. Postgrad Med J. 1998;74:480e1

[6]. Braunwald E,Fauci AS,Kasper DL,Hauser SL,Longo DL,jameson JL:Diabetes mellitus.Harrison's Priciples of Internal Medicine,ed 17,$2008 ; 2275-23$

[7]. Brooks AP, Metcalfe J, Day JL, Edwards MS. Iron deficiency and glycoslated hemoglobin A. LANCET $1980 ; 2: 141$

[8]. Vishal Kalasker 1*, Sudhamadhuri2, M V Kodliwadmath3, Harish Bhat. Effect of Iron Deficiency Anemia on Glycosylated Hemoglobin Levels in Non Diabetic Indian Adults. International Journal of Medical and Health Sciences, Jan 2014;Vol- 3;Issue-1 p-40-43.

[9]. Balasubramanian Shanthi et al., Effect of Iron Deficiency on Glycation of Hemoglobin Journal of Clinical and Diagnostic Research. 2013 January, Vol-7(1): 15-17 in Non Diabetic.

[10]. Alap L. Christy, Poornima A. Manjrekar*, Ruby P. Babu, Anupama Hegde, and Rukmini M.S. Influence of Iron Deficiency Anemia on Hemoglobin A1C Levels in Diabetic Individuals with Controlled Plasma Glucose Levels. Iranian Biomedical Journal, April 2014; 18 (2): 88-93

[11]. Hansen PG, Eriksen J, Andersen TM, Olesen L. Glycosylated haemoglobin (HbA1c) in iron and vitamin B12 deficiency. J Intern Med. 1990;227:133-36

[12]. Rai KB, Pattabiraman TN. The glycosylated haemoglobin levels in iron-deficiency anaemia. Indian J Med. 1986;83:234-36

[13]. Brooks AP, Metcalfe J, Day JL, Edwards MS. Iron deficiency and glycosylated haemoglobin A1. Lancet. 1980;19(ii):141

[14]. Stetler C, Mueller B, Diem P. What you always wanted to know about HbA1c. Schweiz Med Wochenschr. 2000; $130: 993-1005$. 